\title{
Percutaneous treatment of mitral valve regurgitation
}

\author{
Tratamiento percutáneo de la regurgitación mitral
}

Rodrigo M. Lago', Igor F. Palacios²

\begin{abstract}
Mitral Regurgitation (MR) is the most common type of valvular insufficiency. It is estimated that approximately 5 million people in the US and over 20 million worldwide suffer from congestive heart failure, many of whom are associated with dilated ventricles and coexisting MR. Ischemic cardiomyopathy is the most common cause of heart failure in the United States. This disease is marked by diffuse myocardial damage, left ventricular remodeling, and often functional ischemic MR. While surgery can be effective in treating MR, it is frequently associated with high operative morbidity, disease recurrence and increased mortality. Currently, potential percutaneous options for the treatment of mitral regurgitation are in different stages of development either under early phases of clinical use or being pre-clinically tested. These techniques include leaflet coupling with edge-to-edge repair (EValve MitraClip, Edwards Stitch), coronary sinus reshaping (Monarch device, Carillon device, Miltralife ev3, Cardiac Dimensions, Viacor), annular plication with posterior annulus reshaping (Mitralign, Guided Delivery Systems), and left ventricular remodeling (Myocor, Ample PS3). In this article, we will discuss current options and future directions for the percutaneous treatment of mitral valve regurgitation.
\end{abstract}

Palabras claves: mitral regurgitation, valvular insufficiency, percutaneous repair of mitral insufficiency.

\begin{abstract}
RESUMEN
La regurgitación mitral es la más común de las insuficiencias valvulares. Se estima que alrededor de 5 millones de personas en los Estados Unidos y más 20 millones alrededor del mundo sufren insuficiencia cardíaca congestiva, en muchas de las cuales se asocia ventrículos dilatados e insuficiencia mitral coexistente. La cardiomiopatía hipertrófica es la causa más común de insuficiencia cardíaca en EE.UU. Esta enfermedad se caracteriza po daño miocárdico difuso, remodelamiento del ventrículo izquierdo y, frecuentemente, insuficiencia mitral isquémica funcional. Mientras el tratamiento quirúrgico puede ser efectivo para el tratamiento de la regurgitación mitral, está frecuentemente asociado a morbilidad operatoria, recurrencia de la enfermedad y aumento de la mortalidad. Actualmente las opciones percutáneas para el tratamiento de la insuficiencia mitral están en diferentes estadios de desarrollo. Estas incluyen técnicas de plastia mitral percutánea, uniendo los bordes libres de ambos velos mitrales (EValve MitraClip, Edwards Stitch), remodelamiento del seno coronario (Monarch device, Carillon device, Miltralife ev3, Cardiac Dimensions, Viacor), plicatura anular con posterior remodelamiento del anillo (Mitralign, Guided Delivery Systems) y remodelamiento ventricular izquierdo (Myocor, Ample PS3). En este artículo discutimos las opciones terapéuticas actuales y las perspectivas futuras para el tratamiento percutáneo de la insuficiencia mitral.
\end{abstract}

Key words: insuficiencia valvular, regurgitacion mitral, tratamiento percutáneo de la valvula mitral.

Revista Argentina de Cardioangiología Intervencionista 2014;5(3):175-184

\section{INTRODUCTION}

Mitral Regurgitation (MR) is the most common type of valvular insufficiency. It is estimated that approximately 5 million people in the US and over $20 \mathrm{mi}-$ llion worldwide suffer from congestive heart failure, many of whom are associated with dilated ventricles and coexisting MR. ${ }^{1-3}$ Ischemic cardiomyopathy is the most common cause of heart failure in the United States. This disease is marked by diffuse myocardial damage, left ventricular remodeling, and often functional ischemic MR. ${ }^{3}$ While surgery can be effective in treating $\mathrm{MR}$, it is frequently associated with high operative morbidity, disease recurrence and increased

1. Orlando Heart \& Vascular Center Florida Hospital Orlando, FL 32825

2. Director of Interventional Cardiology Massachusetts General Hospital. Professor of Medicine Harvard Medical School. Boston, MA, 02114 mortality. ${ }^{3-5}$ Currently, potential percutaneous options for the treatment of mitral regurgitation are in different stages of development either under early phases of clinical use or being pre-clinically tested. These techniques include leaflet coupling with edge-to-edge repair (EValve MitraClip, Edwards Stitch), coronary sinus reshaping (Monarch device, Carillon device, Miltralife ev3, Cardiac Dimensions, Viacor), annular plication with posterior annulus reshaping (Mitralign, Guided Delivery Systems), and left ventricular remodeling (Myocor, Ample PS3). In this article, we will discuss current options and future directions for the percutaneous treatment of mitral valve regurgitation. Percutaneous mitral valve repair (MVR) is used to treat mitral regurgitation. ${ }^{6-10}$ Percutaneous procedures used to treat valvular heart disease were first developed decades ago; the first pulmonic balloon valvuloplasty was reported in 1982 and was quickly followed by applications to the aortic and mitral valves. Over the past 20 years, percutaneous mitral balloon valvuloplasty used to treat rheumatic mitral stenosis has yielded excellent success rates in patients with suitable valvular and sub- 

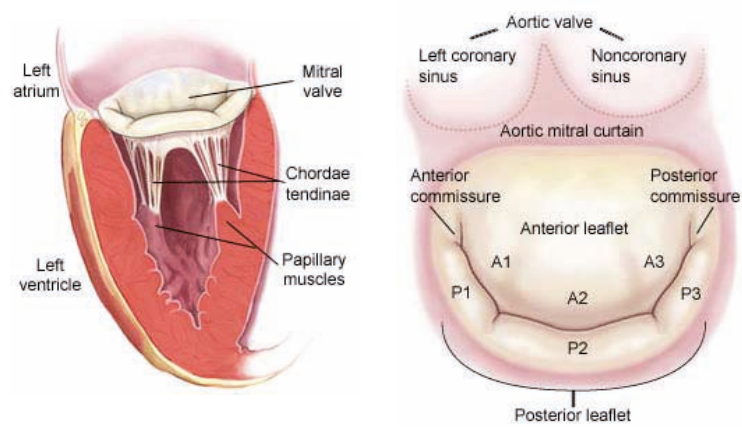

Figura 1.

valvular morphology. However, clinically viable percutaneous treatments for mitral regurgitation have become available only recently. ${ }^{8-12}$

Newer approaches have progressed far beyond balloon valvuloplasty to include catheter techniques for emulating surgical annuloplasty and edge-to-edge repair of regurgitant mitral valves. These are still in early-stage clinical (or preclinical) testing, and the ultimate degree of clinical success and adoption is still unclear. Given the outstanding results of open valve repair, surgery has remain the criterion standard for most cases of symptomatic valvular heart disease. . $^{3-5,13-21}$

In the near term, percutaneous valve intervention will probably have two indications, as follows:

\ Severe disease deemed inoperable owing to comorbid disease

¿ Early-stage regurgitant lesions if less-invasive valve repair may prevent progressive ventricular enlargement.

Although definitive catheter-based therapies for valvular heart disease are clearly in their infancy, various percutaneous approaches are now being evaluated and used. ${ }^{8-12}$ The field is likely to develop rapidly over the next several years, with refinement of the above approaches and emergence of still newer technologies. The landscape of clinical trials is also still under active discussion; if these percutaneous techniques are to be considered as alternatives to traditional surgical methodologies in low-risk to medium-risk patients, they must demonstrate hemodynamic effects, safety, and durability comparable to those of the current highly refined surgical techniques. Conversely, these percutaneous techniques may be best applied to patients at the margins of current surgical indications.

The normal function of the mitral valve is complex and differs from the other heart valves. It depends of the appropriate function and integrity of the 6 components of the mitral valve apparatus, which include the left atrial wall, the mitral annulus, the mitral leaflets,

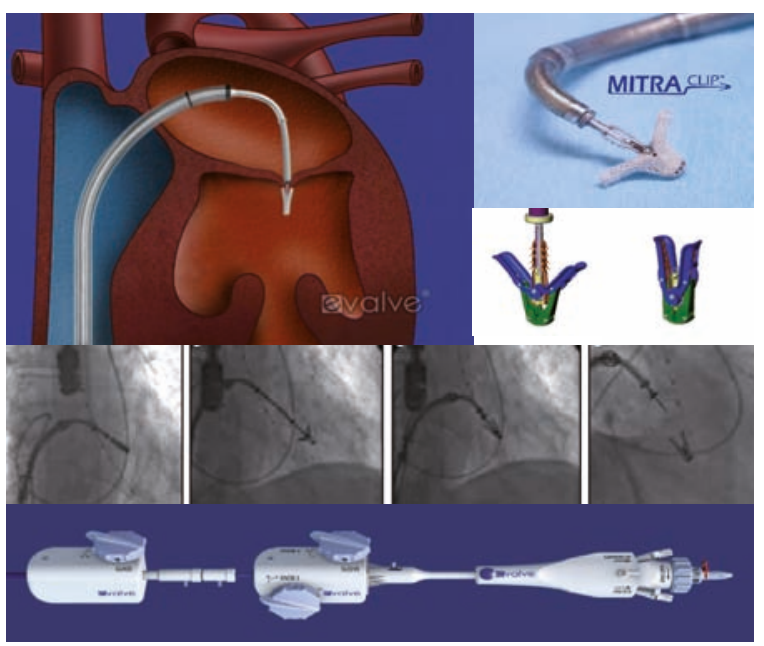

Figura 2.

the chordae tendineae, the papillary muscles, and the left ventricular wall. Any congenital or acquired disorder of individual components of the mitral valve apparatus can disturb the finely coordinated mechanisms of the mitral valve and result in an incompetent valve. It is important to understand the anatomical and functional substrate underlying the development of MR. The mitral valve is a complex anatomical structure and its proper function strictly depends on the structural and functional integrity of its individual components (Figure 1). Abnormalities in one or more of its components can result in stenosis or regurgitant valvular dysfunction. The distinction between primary and secondary (functional) MR is important in order to understand the potential role of percutaneous device therapies for MR. In primary organic MR there is an abnormality of the mitral valve components itself while conversely, in secondary functional MR the mitral valve itself is usually unaffected. However, previous damage of the left ventricle by coronary artery disease or by dilated cardiomyopathy can cause malcoaptation of anatomically normal mitral leaflets in the setting of geometric distortion of the left ventricle, with displacement of papillary muscles and/or annular dilatation with subsequent MR. Functional MR has been associated with an adverse prognosis among patients with dilated and ischemic cardiomyopathy. While surgical intervention is associated with improved symptoms of heart failure and reverse remodeling of the left ventricle, surgical treatment of functional MR has not been shown to improve survival. ${ }^{8}$ Nowadays, mitral valve repair with reduction annuloplasty rather than replacement is favored for the treatment of functional MR. Lessons from surgical experience showed that mitral valve repair can effectively treat many but not all patients with functional MR. Potential factors that can predict the recurrence of MR after mitral repair include annular ring geometry, chordae tendineae repositioning, concomitant reshaping of the LV during repair, and the need for a ¿complete $^{\circ}$ (D-shaped) annuloplasty ring rather than 
TABLE 1. Current Status of Percutaneous Mitral Valve Repair Procedures.

\begin{tabular}{|l|l|l|l|}
\hline & & & \\
\hline Approach & Device & Manufacturer & Status \\
\hline Edge-to-Edge Leaflet Repair & MitraCLip & Mobius & Evalve \\
& Edwards Lifesciences & $\begin{array}{l}\text { Trial - EVEREST } \\
\text { FIH - not under active investigation }\end{array}$ \\
\hline Indirect Annuloplasty & Carilon & Cardiac Dimensions & Trial - AMADEUS \\
& PTMA & $\begin{array}{l}\text { Viacor } \\
\text { ev3 }\end{array}$ & FIH \\
& Mitralife & Edwards Lifesciences & Trial - EVOLUTION \\
\hline Direct Annuloplasty & Monarc & Mitralign & Pre-clinical testing \\
& Mitralign & Guided Delivery Systems & Pre-clinical testing \\
& Pre-clinical testing \\
\hline Ventricular Remodeling & QuantumCor & MuantumCor & FIH \\
\hline Atrial/CS Remodeling & iCoapsys & Ample Medical & FIH \\
& PS3 & Pt. Jude Medical & Pre-clinical testing \\
\hline
\end{tabular}

a Æpartial ${ }^{\circ}$ (C-shaped) ring. ${ }^{11}$ Until recently, available treatment options for functional MR were limited to open surgical repair or replacement, an option that is often challenged and associated with high operative morbidity, disease recurrence, and increased mortality. ${ }^{3-5,8-12}$ The most common form of mitral valve repair involves annuloplasty, the placement of a ring around the mitral annulus to reduce the mitral valve orifice by decreasing the distance between the septal and lateral dimensions of the mitral valve therefore bringing the leaflet edges closer together. Annuloplasty is used as an adjunctive therapy in most forms of mitral valve repair including functional MR. A less commonly utilized surgical leaflet repair approach pioneered by Alfieri et al. is the edge-to-edge repair that creates a double-orifice mitral valve by suturing the free edges of the mitral leaflets together to form a double orifice. Although the isolated use of this surgical technique has been controversial because of the concomitant use of annuloplasty with most leaflet repairs, follow-up for as long as 12 years in patients who have undergone isolated surgical edge-to-edge repair without annuloplasty has demonstrated durable clinical outcome with this surgical technique. ${ }^{30-34}$ Over the past decade, potential percutaneous catheter-based treatment strategies for valvular heart disease have emerged as an attractive option. Percutaneous therapis for MR try to emulate surgical approaches that have been in use for many years.

\section{PERCUTANEOUS TREATMENT OF MITRAL VALVE REGURGITATION}

In general, strategies for transcatheter treatment of MR fall into 1 of 4 groups: 1. Leaflet coupling with edge-to-edge repair which aim to simulate the Alfieri stitch procedure; $;^{30-34} 2$. Coronary sinus reshaping devices (Indirect annuloplasty); $35-48$ 3. Annular plication with posterior annulus reshaping (Direct annuloplasty); and 4. Left ventricular remodeling devices (Table 1).

\section{Percutaneous Edge-to Edge Repair}

The Alfieri surgical technique to treat degenerative and functional MR was introduced in the early 1990s by Dr. Alfieri and colleagues. ${ }^{31}$ Although initially poorly accepted, the 区Alfieri stitch ${ }^{\circ}$ or 区edge-to-edge ${ }^{\circ}$ technique gained popularity. ${ }^{30-34}$ The technique consisted of suturing the free edges of the middle anterior (A2) and posterior (P2) mitral leaflets and creating a double orifice inlet valve. The technique was aimed to improve leaflet coaptation and therefore decrease MR. Long-term Results from this technique were reported for both degenerative and functional MR with 5-year freedom from recurrent MR more then 2+ and re-operation rates of as high as $90 \% .^{30-34}$ The development of transcatheter mitral valve edge-to-edge repair techniques was based on the surgical technique. Two mitral valve percutaneous techniques and devices have been developed ${ }^{30-34}$ to emulate the double orifice strategy using a catheter-based approach: The Evalve MitraClip (Evalve Inc., Menlo Park, California) and the MOBIUS system (Edwards Lifesciences Corp., Irvine, California).

The Evalve MitraClip (Figure 2) is a device that uses a guide catheter that is placed using transseptal puncture, a delivery catheter, and an implantable 4-mm-wide cobalt-chromium implant clip with 2 arms covered with polyester fabric (Figure 2). The device uses a triaxial catheter system to deliver its clip fixation device and create a double-orifice mitral valve. Following the initial encouraging results in animal models, this transcatheter technique had its first in human experience in 2003. ${ }^{31}$ During 2-year follow-up after $\mathrm{Mi}$ traClip implantation, a 56 year-old woman with heart failure and severe 4+ MR, remained asymptomatic with less than $2+$ MR. ${ }^{31-32}$ The safety and feasibility of the MitraClip system was tested in the EVEREST (Endovascular Valve Edge-to-Edge Repair Study) phase I and phase II studies. ${ }^{32-34}$ Results from the $107 \mathrm{pa}-$ tients (55 from EVEREST I; 52 from EVEREST II) with either degenerative (79\%) or functional MR (21\%) were encouraging. In an intent-to-treat basis, implant success occurred in $90 \%$ of patients, in which acute success (MR grade less or equal then $2+$ ) was reported in $84 \%$ of the cases. Among these patients, improvement in NYHA functional class was reported in $73 \%$ at 1-year follow-up. Partial clip detachment occu- 
rred in $9 \%$ of the initial cohort and was the most important mechanical problem with the procedure. This complication was often detected at the protocol-mandated 30-day echocardiogram. These partial detachments were generally not associated with symptoms and most were treated either with surgery or second clip placement. Midterm durability of the MitraClip in the EVEREST study have been recently reported and showed low rates of morbidity and mortality and with acute MR reduction to less then or equal to $2+$ in the majority of patients. ${ }^{34}$ The initial 107 patients were analyzed. $9 \%$ had a major adverse event, including 1 nonprocedural related death. There were no clip embolizations. Partial clip detachment occurred in 9\% patients. Overall, $74 \%$ of the patients achieved acute procedural success, and $64 \%$ were discharged with MR of less then or equal to $1+.30 \%$ of the patients underwent mitral valve surgery during the 3,2 years after MitraCLip implantations. When surgical mitral valve repair was planned, $84 \%$ ( 21 of 25 patients) were successful. Thus, surgical options were preserved. A total of $66 \%$ of the successfully treated patients were free from death, mitral valve surgery, or MR more or equal to $2+$ at 12 months, which was the primary efficacy end point of the study. Freedom from death was $95.9 \%, 94.0 \%$, and $90.1 \%$, and freedom from surgery was $88.5 \%, 83.2 \%$, and $76.3 \%$ at 1,2 , and 3 years, respectively. Similar acute results and durability was observed among the 23 patients with functional MR enrolled in the study. A recently reported hemodynamic substudy of the EVEREST study demonstrated that successful MV repair with the MitraClip system resulted in an immediate and significant improvement in forward stroke volume, cardiac output, and left ventricular loading conditions, without evidence of a low cardiac output state following MitraClip treatment for MR, a complication occasionally observed after surgical mitral valve repair for severe MR (34). The EVEREST II trial, a prospective, randomized, phase II, multi-center study between the US and Canada comparing MitraClip with either surgical valve repair or replacement in 279 patients randomized in a 2-to1 fashion. 12-month follow-up have shown that, despite being driven by a higher incidence of blood transfusions in the surgical group, safety endpoints were reached in about $50 \%$ of surgery patients and $15 \%$ of MitraClip patients, showing superiority of safety for the percutaneous approach by intention to treat. The 1 -year efficacy endpoint of the combined incidence of death, mitral valve surgery, or reoperation for mitral valve dysfunction was more frequent in the surgery patients and in than in the MitraClip patients, meeting the noninferiority hypothesis for efficacy. Similar reductions in left ventricular volumes and dimensions, and improvements in New York Heart Association functional class were achieved in both groups after one year.

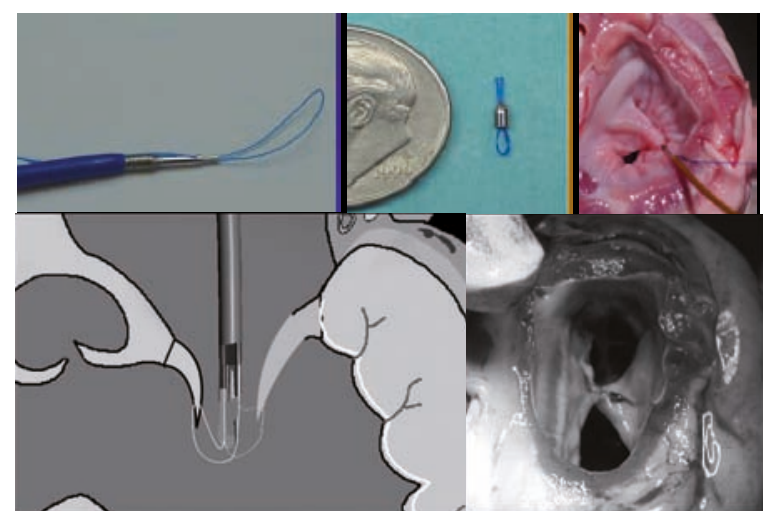

Figura 3. The Milano Stitch/Mobius device.

Careful evaluation and patient selection is critical for success of the procedure. Patients with degenerative or functional MR are candidates for the procedure. A coaptation length of at least $2 \mathrm{~mm}$ is needed. With a flail mitral leaflet, a flail gap less or equal to $10 \mathrm{~mm}$ or a flail width on short-axis estimation less than $15 \mathrm{~mm}$ are required. The MR jet must arise from the central two-thirds of the line of coaptation as seen on shortaxis color Doppler examination and the baseline mitral valve area should be more than $4 \mathrm{~cm}^{2}$ to avoid the creation of mitral stenosis. Technically, the procedure is performed with general anesthesia, using fluoroscopy and transesophageal echocardiography (TEE). Transseptal access is used to place a guide catheter into the left atrium. The Evalve MitraClip guide catheter is 24-Fr proximally and tapers to 22-Fr distally at the level of the atrial septum. It is inserted from the femoral vein and advanced above the mitral valve following a transseptal puncture. The steering knob at the end of the guide allows flexion and lateral movement of the distal tip so that the clip is positioned orthogonally over the three planes of the mitral valve and the origin of the regurgitant jet. The delivery catheter passes coaxially through the guide, and has the MitraClip attached to its distal end. The clip arms are opened and closed by a knob on the delivery catheter handle. The opened span of the clip is approximately $2 \mathrm{~cm}$ and the width is $4 \mathrm{~mm}$. Through the guide catheter, the delivery system is maneuvered to center the clip over the mitral orifice, the clip is partially opened and passed across the leaflets into the left ventricle. The open clip is then pulled back to grasp the mitral leaflets and the clip is closed. The degree of MR is assessed by TEE. If necessary, the clip can be reopened, the mitral leaflets released, and the clip repositioned. If needed, a second clip can be placed. Once optimal reduction of MR is achieved the clip is released from the delivery system and both the delivery system and guide catheter are withdrawn. Repeat hemodynamic, angiographic, and echocardiographic assessments are routinely performed. Heparin is routinely used during the procedure and administered to achieve an activated clotting time of 250 seconds or more. Aspirin 325 
$\mathrm{mg}$ and clopidogrel $75 \mathrm{mg}$ daily are ordinarily recommended following the procedure for 6-months and 30 days respectively. Importantly, clip failure is well tolerated and does not preclude surgical mitral valve repair or replacement.

Four year follow up results of the EVEREST II trial showed that at 4 years, patients with mitral valve regurgitation who undergo repair with a novel percutaneous device experience mortality rates and mitral regurgitation (MR) levels comparable to those that accompany surgery, according to updated data from the EVEREST II (Figure 3). While surgery continues to hold an early advantage in MR and need for surgical reintervention, few differences between treatment groups were apparent beyond 1 year. The EVEREST II trial randomized 279 patients with moderately severe or severe (grade 3+ or 4+) MR in a 2:1 ratio to percutaneous treatment with the MitraClip system (Abbott Vascular; Santa Clara, CA; $\mathrm{n}=184$ ) or surgical repair or replacement $(\mathrm{n}=95)$.

At 1 year, rates of the primary efficacy endpoint, a composite of freedom from death, surgery for mitral valve dysfunction, and grade $3+$ or $4+\mathrm{MR}$, favored surgery ( $73 \%$ vs. $55 \% ; P=0.007)$, with need for surgical intervention for mitral valve dysfunction tenfold lower than in the percutaneous group ( $2 \%$ vs. $20 \%$; $P$ $<0.01)$. However, the percutaneous approach was safer (30-day MACE $15 \%$ vs. $48 \%$; $P<0.001$ ).

Although at 4 year follow up the composite efficacy endpoint was numerically higher with surgery the difference was no longer significant $(39.8 \%$ vs. $53.4 \%$; $\mathrm{p}=0.070)$. Rates of mortality $(17.4 \%$ vs. $17.8 \% ; \mathrm{p}=$ $0.914)$, and moderate-to-severe and severe MR (21.7\% vs. $24.7 \%$; $p=0.745$ ), were comparable between the groups. ${ }^{38}$ However, the need for surgery for mitral valve dysfunction was almost 5 times greater after percutaneous therapy $(24.8 \%$ vs $5.5 \%$; $\mathrm{p}<0.001)$. In the percutaneous group, 5 patients underwent reintervention with a second MitraClip within the first year. Implantation failed in 1 case, and a second, successful reintervention was performed between the first and fourth years. The majority of the surgeries required for residual regurgitation occurred within the first year after implantation, with only 3 patients undergoing surgical repair after that time point. In the surgical group, 2 patients underwent reoperation over the first 12 months and 2 between years 1 and 4 . The surgical group experienced a greater reduction in MR at discharge and throughout follow-up compared with the percutaneous group (20.6\% vs. $9.1 \%$ at 4 years). ${ }^{38}$ Also at 4 years, the percutaneous and surgical arms showed similar improvements in left ventricular dimensions, except for a larger left ventricular internal diameter, diastolic, in the device group $(5.25 \pm 0.65 \mathrm{~cm}$ vs. $4.84 \pm$ $0.67 \mathrm{~cm} ; P<0.001)$. Likewise, both groups experienced substantial declines in the proportion of patients in NYHA class III or IV from baseline to 12 months
( $45.7 \%$ to $2 \%$ for the percutaneous group, $44.8 \%$ to $13.4 \%$ for the surgical group) that were mostly maintained at 4 years $(5.7 \%$ and $6.3 \%$, respectively). Similar to the 1-year results, analysis at 4 years showed interaction for age ( $<70$ vs. $\geq 70 ; P=0.025)$ and the etiology of MR (functional vs. degenerative; $P=0.023$ ) with efficacy. In the subgroup with functional MR (n $=66$ ), rates of the composite efficacy endpoint were similar for percutaneous and surgical patients $(34.1 \%$ vs. $22.7 \% ; P=0.344)$. Furthermore, among those with $3+$ or $4+$ regurgitation, functional MR was more prevalent in the surgical arm than the percutaneous arm In summary, EVEREST II at 4 Years shows that Surgery Maintains Early Advantage, But MitraClip is Durable. Thus, while the percutaneous approach remains promising, 区the data don yet tell us that we have a device solution that is as good as the surgical solution and therefore $\bigotimes$ Surgery remains the standard therapy. ${ }^{038}$

The MOBIUS Leaflet Repair system (Edwards Lifescience Inc., Irvine, California), also called $\varangle$ Milano Stitch $^{\circ}$ (Figure 3), was introduced by Dr. Buchbinder and colleagues as a similar catheter based edge-to-edge technique. Contrary to the Evalve MitraClip, this strategy uses a small guiding catheter to stitch the free edges of the anterior and the posterior mitral leaflets thus creating a double orifice inlet valve. An innovative suction catheter is utilized to bring the leaflets together and facilitate stitch placement under fluoroscopic and echocardiographic guidance. Following the successful animal model experience, the first in-human case was performed in Milan, Italy in a 67 year-old woman with NYHC functional class III and severe (grade 4+) MR secondary to a prolapsed posterior leaflet. Subsequently, the percutaneous $\triangle$ Alfieri-like stitch ${ }^{\circ}$ was tested in a feasibility trial of 15 patients with either degenerative or functional MR. In this phase I study, acute procedure success occurred in 9 of 15 patients. Of these, 3 patients required a single stitch, 5 required two stitches, and one patient required three stitches. At 30 day follow-up only $66 \%$ of the patients (6 of 9) had a successful stitch in place with at least one grade improvement in MR reduction. The acute failure patients ( 6 of 15) all underwent subsequent successful surgical re-

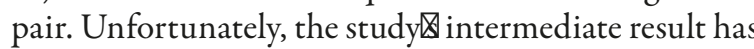
prompted the investigators to abandon further evaluation for this particular indication.

\section{Percutaneous Annuloplasty - Indirect Annuloplasty techniques}

Annuloplasty is the mainstay of surgery in patients with functional MR. Annular dilation due to dilation of the left ventricle and geometric distortion of the mitral apparatus is the mechanism of MR in this group of patients. Surgical mitral annuloplasty typically involves a complete ring to reshape the entire mitral annulus. Partial annuloplasty is believed to be ineffective. Percutaneous annuloplasty approaches can be ei- 


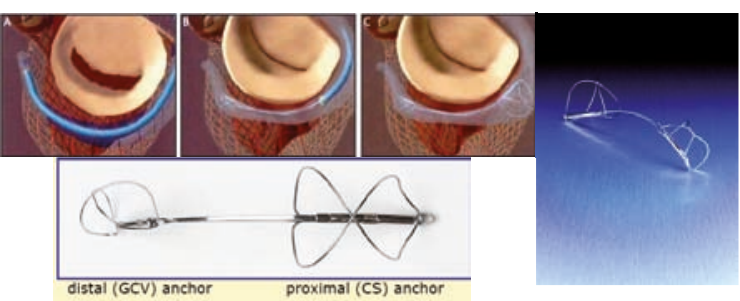

Figura 4. Years Follow-Up of the EVEREST II Trial.

ther direct or indirect. Indirect approaches use the coronary sinus as a route to deliver a device to partially wrap the mitral annulus parallel to the posterior mitral valve leaflet and create tension that is transmitted to the mitral annulus. The rational being that any conformation change of the coronary sinus may be used advantageously to reduce the septal-lateral annular dimensions and improve MR severity. Indirect annuloplasty approaches include the Cardiac Dimensions Carillon system (Cardiac Dimensions, Kirkland, Washington), the Edwards Monarc system (Edwards Lifesciences, Irvine, California), the Mitralife/ev3 device, and the Viacor PTMA system (Viacor, Wilmington, Massachusetts). Direct annuloplasty approaches involve direct implantation of a device into the mitral annulus which more closely mimics surgical anuloplasty. Direct annuloplasty devices include the Mitralign system (Mitralign, Tewksbury, Massachusetts) and the Guided Delivery Systems device (Guided Delivery Systems, Santa Clara, California).

The Cardiac Dimensions Carillon device (Cardiac Dimensions, Kirkland, Washington) (Figure 4) system combines an implantable device and delivery system. The device consists of two anchors connected by a nitinol bridge. Via jugular access under fluoroscopic guidance, a 9-F guide catheter is delivered into the distal coronary sinus. A distal anchor is placed distally in the great cardiac vein and a proximal anchor is placed proximally near the ostium of the coronary sinus. Once the distal anchor is deployed into the great cardiac vein, tension is applied to the system resulting in immediate decrease in the diameter of the mitral annulus, by moving the posterior leaflet more anteriorly. Then, the proximal anchor is released. Simultaneous TEE allows for direct visualization of MR improvement. The Carillon Mitral Contour System is simple quick and easy to use. It is adjustable and can apply varying degrees of tension to system. It is compatible, as it fits contours of various anatomies allowing for optimal and safe delivery to occur. A major advantage of this device is that it is retrievable if positioning is not optimal. Its intuitive delivery system comes in sizes of $60 \mathrm{~mm}$ in length with a 7-14 mm distal anchor height and $12-20 \mathrm{~mm}$ proximal anchor height $(1.5 \pm 2.0$ Ratios). The issue with the first generation of the device in which there was a difficulty in anchoring was corrected with improvements in engineering (Carillon ${ }^{\mathrm{TM}}$
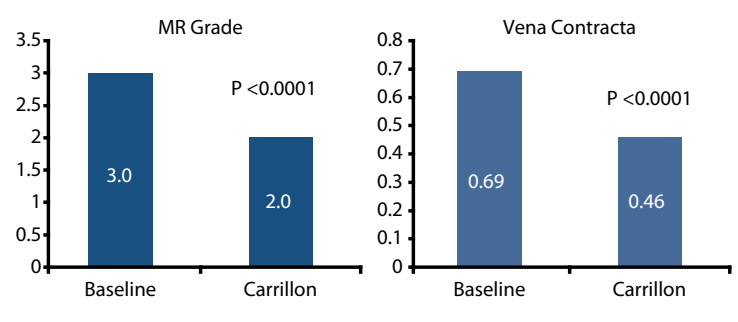

Effective Regurgitant Orifice

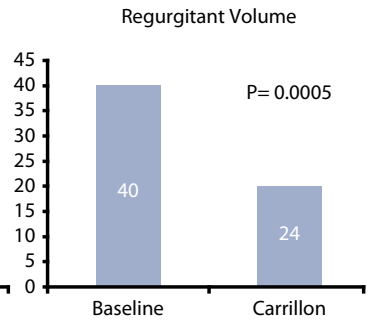

Figura 5. Amadeus trial results.

$\mathrm{XE}$ ). Initial experiments in animals showed that placement of the Carillon system in 6 dogs dilated cardiomyopathy resulted in both a mean decrease in mitral annulus diameter from $2.7 \pm 0.2 \mathrm{~cm}$ to $2.3 \pm 0.1 \mathrm{~cm}$ $(\mathrm{p}<0.05)$, and a mean decrease in MR/left atrial area ratio from $16 \pm 4$ to $4 \pm 1(\mathrm{p}=0.052) .^{38}$ The first in-human implantation of the Carillon device was performed by Dr. Schofer in Hamburg, Germany. Recently, the AMADEUS trial (cArillon Mitral Annuloplasty Device European Union Study), a prospective single arm multicenter safety and efficacy trial of the Carillon system, was reported. The primary endpoint of the study was safety of deployment and implantation of the device in the coronary sinus and the great cardiac vein. The secondary endpoint included long-term safety and effect of the device on hemodynamic parameters and subject function. The study enrolled $48 \mathrm{pa}-$ tients with follow-up at 1-, 3-and 6-month intervals. Candidate patients with $\mathrm{CHF}, \mathrm{MR}\left({ }^{3} 2+\right)$ and decrease left ventricular systolic function $(\mathrm{EF}<40 \%)$ for the trial underwent a standardized 6 minute walking test, a TEE, a treadmill test, and a multi-slice CT scan to determine the anatomical relationship between the coronary sinus, the mitral annulus ring, and the left circumflex coronary artery. Angiographic examination of the coronary sinus and the coronary arteries were acquired prior to device implantation. The study initially enrolled 4 patients with between July of 2005 and March of 2006, showed successful permanent device implantation in only one patient. This patient had successful reductions in MR severity and improvement in functional status that persisted at 6 months follow-up. In the remaining three patients, the device moved as the distal anchor was unable to consistently maintain its shape during device tensioning prior to final deployment. Nevertheless, the devices were recaptured and removed safely. Successful implantation occurred in $70 \%$ of the patients, and resulted in improved functio- 


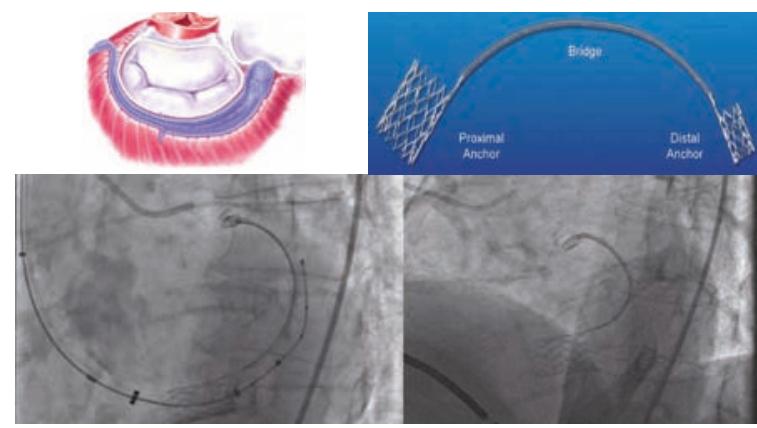

Figura 6. Monarc device

nal class and MR severity of at least $1+$ in $80 \%$ of the cases. Those who benefited most had evidence of congestive heart failure and $\geq 2+$ centric MR secondary to mitral annulus dilatation. Acute MR reduction (grade $3.0+/-0.6$ to $2.0+/-0.8$, $\mathrm{p}<0.0001)$ and permanent implantation were achieved in 30 of 43 patients in whom an attempt was made. Additional measurements in 20 patients with implants showed reductions in the vena contracta $(0.69+/-0.29$ to $0.46+/-0.26$ $\mathrm{cm}, \mathrm{p}<0.0001)$, effective regurgitant orifice area $(0.33$ $+/-0.17$ to $\left.0.19+/-0.08 \mathrm{~cm}^{2}, \mathrm{p}<0.0001\right)$, regurgitant volume $(40+/-20$ to $24+/-11 \mathrm{ml}, \mathrm{p}=0.0005)$, and jet area/left atrial area $(45+/-13 \%$ to $32+/-12 \%$, p $<0.0001)$ (Figure 5). The coronary arteries were crossed in 36 patients (84\%) (Figure 5). One major limitations of this device is the potential obstruction of left circumflex coronary artery flow during device deployment. In $84 \%$ of the patients, the device crossed the left circumflex coronary artery, in which compromise of blood flow occurred in $14 \%$, in whom the device was immediately retrieved. Overall, the AMADEUS study achieved its safety endpoint with an acceptable adverse event profile. MR was reduced by $27 \%$ out to 6 months and the patients had significant improvements in functional parameters out to 6 months. ${ }^{40}$

The Edwards Monarc system (Edwards Lifesciences, Irvine, California) is percutaneously implanted in the coronary sinus after cannulation with a guide catheter. The device is designed to improve MR severity over an estimated 3 to 6 week period remodelling the mitral annulus by implanting a bioabsorbable spring-like \bridge ${ }^{\circ}$ that is connected between two self-expanding proximal and distal nitinol stents (Figure 6). The procedure is performed in under local anesthesia via $12 \mathrm{Fr}$ right transjugular approach. The stent anchors provide force that brings the proximal coronary sinus and distal great cardiac vein together while the interconnecting bridge tenses and foreshortens over time. The conformational changes invoked over the posterior annular segment presumably shorten of the septal-lateral dimensions to reduce MR severity. The first human experience with the Monarc system was reported by Dr. Webb et al. in 2006 and included 5 patients with chronic severe ischemic MR. ${ }^{31}$ Implantation was successful in 4 of the 5 patients, and resulted in mean decrease
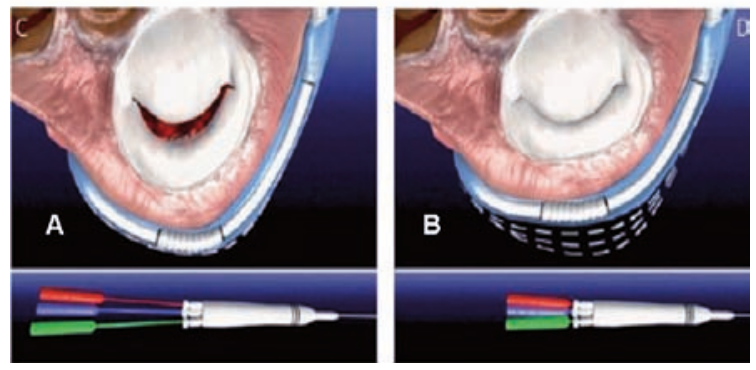

Figura 7. The Viacor PTMA system

in MR grade from 3+ to 1+. Loss of efficacy was later seen in 3 of the patients due to asymptomatic separation and fracture of the bridging segment. Following device modification and reinforcement of the bridging segment the EVOLUTION phase I study was conducted. In this study, successful implantation was achieved in 59 of the 72 patients (82\%) with functional MR and heart failure. Freedom from death, MI, and cardiac tamponade at 30 days was $91 \%$. Left circumflex coronary artery compression occurred in $30 \%$ of patients. Major adverse events at 18 -months included 1 death, 3 myocardial infarctions, 2 coronary sinus perforations, 1 anchor displacement, and 4 anchor separations. This study showed that the Monarc system was feasible to implant, and although efficacy data is encouraging, coronary compression and anchor separations remain important concerns and limitations. The effect of the Edwards Monarc device can not be assessed at the time of placement therefore there is no indication regarding the efficacy outcome until the spring has shortened several weeks later to predict the outcome of MR reduction until weeks have passed. The EVOLUTION II (Clinical Evaluation of the Edwards Lifesciences Percutaneous Mitral Annuloplasty System for the Treatment of Mitral Regurgitation) trial study of the Monarc device has been stopped by the sponsor due to slow enrollment.

The Viacor Percutaneous Transvenous Mitral Annuloplasty (PTMA) system (Figure 7) consists of a polytetrafluoroethylene catheter in which different stiffness rods are introduced into the distal part of the coronary sinus via subclavian or jugular venous puncture. A trilumen plastic cannula is delivered into the coronary sinus and nitinol rods are passed through the lumens of the catheter to apply pressure to the the posterior annulus in the central part of the posterior mitral valve leaflet (P2) and compress the septolateral dimension. Following the identification of the optimal amount of compression of the posterior annulus to result in a reduction in MR, permanent implantation is performed. The device can be retrieved in cases of absence of reduction in MR or left coronary circumflex cinching. Preliminary studies in sheep models were highly encouraging and resulted in decrease MR severity from $+3-4$ to $+0-1(P<0.03)$, and associated with significant reductions in septal-lateral mitral annular dimen- 
sions (from $30 \pm-2.1 \mathrm{~mm}$ to $24 \pm 1.7 \mathrm{~mm}$; $\mathrm{P}<0.03$ ). ${ }^{42-}$ ${ }^{46}$ The first in-human feasibility and safety study was reported in 2007 and included 4 patients with ischemic MR and NYHA class II or III, MR $\geq 2+$, type I and/or IIIB Carpentier囚 MR functional class requiring surgical mitral annuloplasty and showed continued reduction of the mitral orifice for as long as 1 year after initial implantation. In this study the device was temporally implanted, adjusted and subsequently removed. The authors report substantial reductions in regurgitant volumes $(45.5+/-24.4$ to $13.3+/-7.3 \mathrm{ml})$ due to the mechanically induced anterior-posterior diameter reduction $(40.75+/-4.3$ to $35.2+/-1.6 \mathrm{~mm})$ in 3 patients. In one patient, the device could not be deployed due to extreme angulated anatomy. Recently, the Canadian and European phase I PTOLEMY (Percutaneous Transvenous Mitral Annuloplasty) trial has been reported. This study included 27 patients with NYHA functional class II or III, and moderate to severe functional MR. ${ }^{41-45}$ Successful implantation was performed in 19 of the 27 patients. The remainders were excluded due to unsuitable coronary sinus anatomy. Of those who underwent successful implantation 13 had a reduction in MR severity and in 6 the device was ineffective. Device removal was required in 4 patients due to fracture or device migration or diminished efficacy. Long-term success in MR reduction was seen in only $18.5 \%$ of the patients. An attractive feature of this device is the ability to re-access the venous access at a later date to remove rods if the reduction of MR is diminished. In that case, stiffer rods may be used to replace the initial implanted rods. The phase II PTOLEMY trial has been presented and showed 2.8\% 30 -day cardiac event rates and $>90 \%$ procedural success. Unfortunately, the company has stopped further development and manufacturing of the device.

Despite the attractive and easy of use and effectiveness of the coronary sinus devices approach, they all have limitations. Metal fatigue and the risk of device fracture due to mechanical stress in the coronary sinus created by torsional forces on these devices is an important issue. Re-engineering of all of these devices has improved outcomes. A second limitation common to this class of devices is the potential for compression of the left circumflex coronary artery. Cardiac computed tomography to assess the relationship of the coronary sinus and the coronary arteries before device implantation is an important step in the evaluation of these patients before annular device implantation.

The MitraLife device (ev3/Edwards Lifescience, Irvine, California) represents one of the first annuloplasty device tested in human. It consists of a percutaneous delivery system that is preloaded with the Mitralife device and is permanently implanted in the coronary sinus via internal jugular approach. The device is designed to reduce mitral annular size, and restore valve leaflet closure. Durability and feasibility results in canine ani- mal models have been thus far promising, and associated with significant reduction in MR. Up to date only a handful of human temporary placements have occurred outside the Unites States. Initial reports of the MitraLife device have been presented. They An experience of 7 patients ( 5 males and 2 females), age 22 to 66 years with functional MR. All patients had severe MR and NYHC III \& IV and the mean ejection fraction was $27 \%{ }^{40-41}$ Significant reductions in mitral annulus and MR were described, however clinical trial is pending.

\section{Direct Annuloplasty techniques}

The Mitralign system (Mitralign, Tewksbury, Massachusetts) involves placement of the guide catheter under the middle scallop of the posterior mitral leaflet. The device consists of a deflectable catheter that is manipulated and advanced in a retrograde fashion across the aortic valve through a $14-\mathrm{Fr}$ femoral sheath into the subvalvular mitral valve space. A steerable catheter with a deflectable two-arm (bident) catheter end is delivered via 12.5-Fr guide catheter between the papillary muscles facing the posterior mitral annulus. Once properly aligned, anchor pledgets are delivered from the left ventricle to the left atrium across the circumferencial mitral valve annulus and pulled together with a guidewire to decrease the annulus septal-lateral dimension. The feasibility and durability of this technique has been confirmed in early animal studies whereby significant reductions in MR were demonstrated. Currently, the technique is being tested in a safety and feasibility phase I clinical study, however preliminary results have yet to be released and clinical outcome data are expected in the future.

The Accucinch device (Guided Delivery Systems, Santa Clara, California) is another promising strategy. A small adjustable ring of anchors interlinked with a cable is implanted percutaneously into the muscle below the mitral valve. The tinching $^{\circ}$ effect improves the ability of the mitral valve to close properly and reduces the mitral regurgitation. After access to the annulus, a series of as many as 12 nitinol anchors are placed in the mitral annulus. These are connected with a cord that is tensioned to draw the anchors together. This device has been implanted surgically, and first-in-human experience has demonstrated the technical feasibility of percutaneous use. The Accucinch system has been successfully tested during open-heart surgery in two patients with $2+\mathrm{MR}$ and coronary arterial disease undergoing routine coronary artery bypass grafting. The surgically implanted device resulted in sustained and successful reductions in MR severity at 6 and 12-month follow-up. The first in-human percutaneous implantation of the Accucinch system for mitral valve repair was reported in 2009. The procedure was performed by Dr. Schofer in Hamburg, Germany and the Accu-

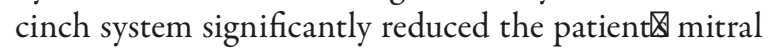
regurgitation. 


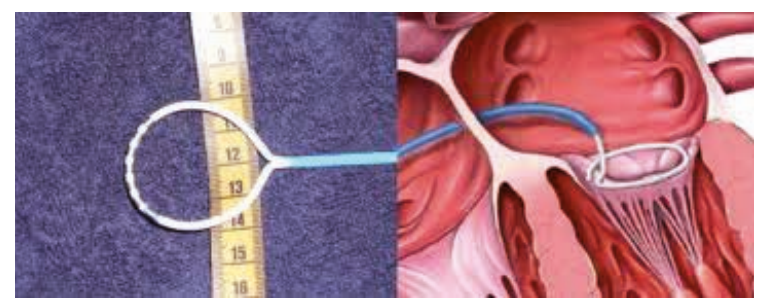

Figura 8. QuantumCor

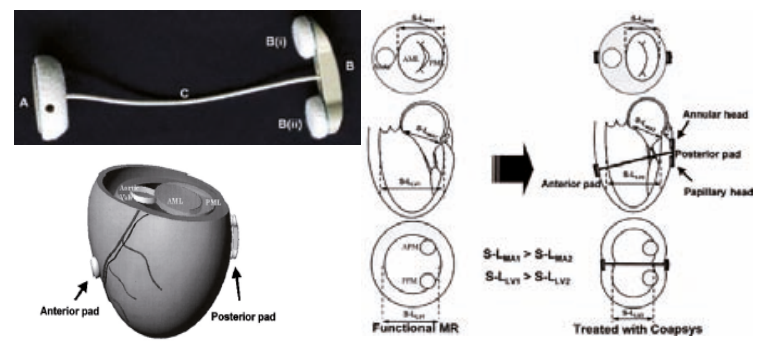

Figura 10. Coapsys device

Although arterial access as the delivery route adds morbidity to the procedure in comparison with a the simplicity and ease of use of the transvenous coronary sinus approach, direct annuloplasty has the advantage of avoiding coronary compression and the potential for greater efficacy in reduction of MR through the direct approach is highly attractive. Direct annuloplasty technologies are in early development, and more human experience is expected.

The QuantumCor system (QuantumCor Inc., Lake Forest, California) (Figure 8) represents a unique and different concept that has yet to be tested in humans. This technology is based on thermal remodeling of collagen (TRC), which uses the high collagen content of the mitral valve annulus in which high frequency energy is delivered through an electrode to denature collagen fibers causing them to shrink and consequently remodeling the annulus. The end-loop catheter electrode system device is positioned on the dilated valve annulus where a precise subablative radiofrequency energy protocol is delivered. This releases the hydrogen bonds in the collagen fibers of the mitral annulus causing them to shrink. The posterior annulus is treated in four quadrants from trigone to trigone achieving segmental shrinkage in each quadrant. Segmental shrinkage in all four quadrants results in a remodeling of the valve annulus, a reduction of the antero-posterior dimension of the valve, and improved coaptation of the valve leaflets. When the procedure is complete, the catheter device is removed and no hardware is left in the heart or vascular system. The technique has been tested in acute and chronic sheep models where up to $20 \%$ reductions in septal-lateral annular dimensions have been reported. ${ }^{48}$ Histopathological examination has shown no evidence of undesirable injury among the vicinity of related structures.

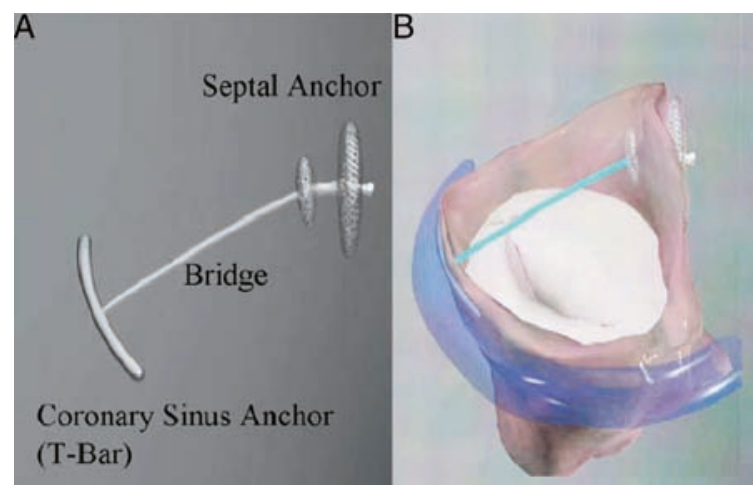

Figura 9. PS3

\section{Remodeling of the Left Ventricular/Left Atrial Mitral Valvular Complex}

This group of transcatheter devices is currently being developed to improve the paravalvular geometric distortion that is encountered in patients with functional MR.

The Percutaneous Septal Sinus Shortening system, also known as PS3 (Ample Medical, Inc.) (Figure 9) is a transcatheter atrial/mitral annulus remodeling device that integrates several concepts and consists of an atrial septal occluder, an interconnecting cinching wire, and a permanent small coronary sinus T-bar element that is positioned behind P2. The interatrial occluder serves as a pivotal anchor and allows cinching to occur from the posterior annulus to the superior medial interatrial septum. The concept was developed based on previous animal studies that showed increase in posterior wall to interatrial septum dimensions in functional MR. The initial experience with the PS3 device was first reported in 23 sheep with dilated cardiomyopathy and functional MR. Immediate and mid-term results at 30 days revealed important reductions in septal to lateral dimensions and MR severity ${ }^{49-50}$ Coronary arterial impingement was not observed, and the great cardiac vein was patent in all animals during follow-up histopathological examination. Significant hemodynamic improvements and a drop in brain natriuretic peptide levels were observed. The feasibility and safety of this technique was first confirmed in two patients undergoing temporary implantation of the PS3 system before mitral valve repair surgery. ${ }^{50}$ In the first patient, the PS3 resulted in a relative change of $29 \%$ in septal-lateral dimension and was associated with a $1+$ decrease in MR severity. The MR severity in the second patient decreased from +3 to +1 following a $31 \%$ relative change in septal-lateral dimension. No procedural complications were reported. The ongoing CAFÉ trial is a phase I safety and feasibility study of longterm PS3 implant in humans with heart failure and severe functional MR.

The iCoapsys (Myocor Inc, Maple Grove, Minnesota) left ventricular reshaping device was until recently a promising alternative percutaneous strategy developed to treat functional MR (Figure 10). Although no lon- 
ger in use, the strategy represents an important concept. The iCoapsys transventricular system consists of an anterior and posterior epicardial pad tethered together by a subvalvular transventricular chord that travels through the left ventricule and between the papillary muscles. After its implantation via subxyphoid pericardial approach, the chord length can be reduced and adjusted to establish optimal septal-lateral LV and annular dimensions. Conformational changes are intended to reorient the papillary muscles and reduce LV geometric distortion, resulting in decrease in regurgitant orifice and MR severity. Promising results were reported from the early animal experience. ${ }^{50}$ Unfortunately, the VIVID (Valvular and Ventricular Improvement Via iCoapsys Delivery) feasibility study in humans was prematurely discontinued due to the technical difficulties during device implantation and suboptimal patient applicability.

\section{Perivalvular Prosthetic Mitral Regurgitation}

Percutaneous repair of perivalvular prosthetic mitral regurgitation has evolved to become yet another important and attractive alternative to surgical correction. Paravalvular mitral regurgitation is a dreadful complication seen in up to $7 \%$ of patients following prosthetic heart valve surgery. ${ }^{52-58}$ In this group of patients, redo-operations are commonly associated with increased procedural mortality. More recently, percutaneous endovascular devices have been experienced with promising results. ${ }^{52-58}$ The Amplatzer Vascular Plug, the Septal Occluder and Duct occluder (AGA Medical Inc. Golden Valley, Minnesota) are used to seal the paravalvular regurgitation. The Amplatzer Duct Occluder represents the most commonly used device. Implantation of two or more devices may be necessary. In our experience, simultaneous 3D TEE imaging should be encouraged for all cases, as it provides optimal information during device implantation (Figure 11).

\section{SUMMARY AND FUTURE DIRECTIONS}

Percutaneous approaches to MR remain largely investigational. However, over the last decade novel

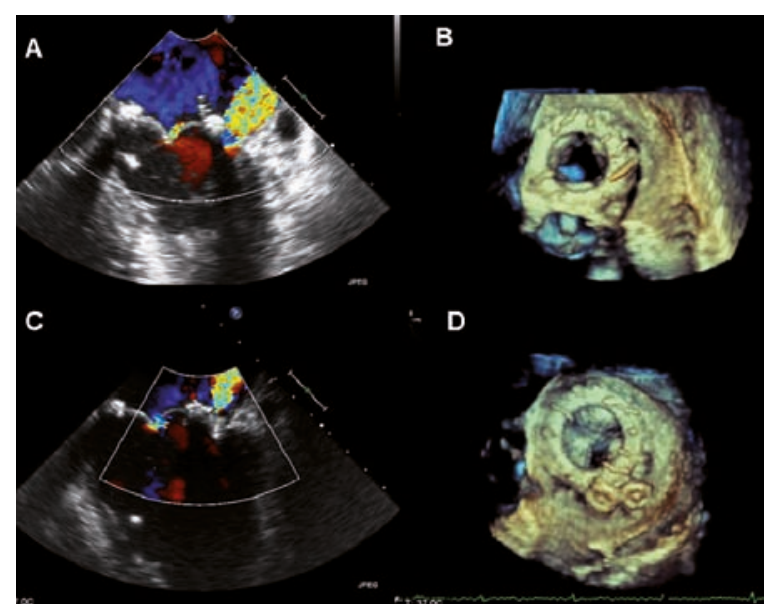

Figura 11. Paravalvular leak 3 D echo

percutaneous strategies for the treatment of valvular heart disease have opened new options in the treatment of valvular heart disease. Animal and early human studies indicate that many of these techniques are safe and feasible. Several important clinical studies are currently underway and will more likely determine the benefits of transcatheter mitral valve repair therapy. It is apparent that given the complexity of the mitral valve apparatus and its subvalvular structure, that a single device to treat all forms of mitral regurgitation is unlikely to be effective in every patient. However, the encouraging results of the $\mathrm{Mi}$ traClip suggests that this technique may eventually play an important role in the treatment of organic MR. Contrarily, the role for isolated coronary sinus devices remains uncertain. The role of transcatheter left ventricular remodeling devices to treat functional MR is currently at the beginning of its development. Transcatheter chordal procedures are currently under development, including chordal cutting and chordal implantatation. ${ }^{59-60}$ Finally, transcatheter valve implantation in the mitral position might offer a very desirable alternative in selected patients and has been accomplished in a compassionate fashion in rare occasions in patients not candidates for surgical valve repair or replacement.

\section{REFERENCES}

US Census Bureau. Statistical Abstract of the US: 2006, Table 12.

2. GheorghiadeM,Sopko G, De Luca L, VelazquezEJ, ParkerJD, Binkley PF, Sadowski Z, Golba KS, Prior DL, Rouleau JL, Bonow RO. Navigating the crossroads of coronary artery disease and heart failure. Circulation. 2006; 114: 1202-1213.

3. Bonow R.O., Carabello B.A., Chatterjee K., ACC/AHA 2006 guidelines for the management of patients with valvular heart disease: a report of the American College of Cardiology/American Heart Association Task Force on Practice Guidelines (Writing Committee to Revise the 1998 Guidelines for the Management of Patients With Valvular Heart Disease). J Am Coll Cardiol. 2006;48:e1-e148.

4. Patel et al. Mitral Regurgitation in Patients with Advanced Systolic Heart Failure, J of Cardiac Failure, 2004.

5. Lung $B$, et al. A prospective survey of patients with valvular heart disease in Europe: The Euro Heart Survey on Valvular Heart Disease. Eur Heart J. 2003;24:1231-1243.
6. Gammie, J et al, Trends in Mitral Valve Surgery in the United States: Results from the STS Adult Cardiac Database, Annals of Thoracic Surgery 2009.

7. Mirabel $M$, et al. Long-term outcomes and cardiac surgery in critically ill patients with infective endocarditis. Long-term outcomes and cardiac surgery in critically ill patients with infective endocarditis. Eur Heart J. 2007;28:1358-1365.

8. Do Lago, RM, Cubeddu RJ, Palacios, IF. Percutaneous Techniques for the Treatment of Patients with Functional Mitral Valve Regurgitation. Interventional Cardiology Clinic (in press).

9. Rankin, et al, Determinants of operative mortality in valvular heart surgery. J of Thoracic and Cardiovascular Surgery, March 2006

10. Hendrik Treede et al. A Heart Teams Perspective on Interventional Mitral Valve Repair: Percutaneous clip implantation as an important adjunct to a surgical mitral valve program for treatment of high-risk patients; The Journal of Thoracic and Cardiovascular Surgery, 2011 
11. H. Reichenspurner.MitraClip-Data analysisfrom a cardiacsurgeon's pers pective. EACTS 2012

12. Paul Grayburn, et al; Mechanism and Severity of Mitral Regurgitation by Transesophageal Echocardiography in Patients Referred for Percutaneous Valve Repair; Am J Cardiol 2011 Sep 15;108(6):882-7

13. Gillinov AM, Wierup PN, Blackstone EH, Bishay ES, Cosgrove DM, White J, Lytle BW, McCarthy PM. Is repair preferable to replacement for ischemic mitral regurgitation? J Thorac Cardiovasc Surg. Dec 2001;122(6):11251141.

14. Grossi EA, Goldberg JD, LaPietra A, Ye X, Zakow P, Sussman M, Delianides J, Culliford AT, Esposito RA, Ribakove GH, Galloway AC, Colvin SB. Ischemic mitral valve reconstruction and replacement: comparison of long-term survival and complications. I Thorac Cardiovasc Surg. Dec 2001;122(6):1107-1124.

15. Koelling TM, Aaronson KD, Cody RJ, Bach DS, Armstrong WF. Prognostic significance of mitral regurgitation and tricuspid regurgitation in patients with left ventricular systolic dysfunction. Am Heart J. 2002; 144: 524-529.

16. Bursi F, Enriquez-Sarano M, Nkomo VT, Jacobsen SJ, Weston SA, Meverden $R A$, Roger VL. Heart failure and death after myocardial infarction in the community: the emerging role of mitral regurgitation. Circulation. 2005; 111: 295-301.

17. Wu AH, Aaronson KD, Bolling SF, Pagani FD, Welch K, Koelling TM. Impact of mitral valve annuloplasty on mortality riskin patients with mitral regurgitation and left ventricular systolic dysfunction. J Am Coll Cardiol. 2005; 45: 381-387.

18. Bolling SF, Pagani FD, Deeb GM, Bach DS. Intermediate-term outcome of mitral reconstruction in cardiomyopathy. J Thorac Cardiovasc Surg. 1998, 115: 381-388.

19. Bax JJ, Braun J, Somer ST, Klautz R, Holman ER, Versteegh MIM, Boersma E, Schalij MJ, van der Wall EE, Dion RA. Restrictive annuloplasty and COronary revascularization in ischemic mitral regurgitation results in reverse left ventricular remodeling. Circulation. 2004; 110 (suppl): II-103-11-108.

20. Hueb AC, Jatene FB, Moreira LFP, Kallás E, de Oliveira SA. Ventricular remodeling and mitral valve modifications in dilated cardiomyopathy: new insights from anatomic study. J Thorac Cardiovasc Surg. 2002; 124: 1216-1224. Kaji S, Nasu M, Yamamuro A, Tanabe K, Nagai K, Tani T, Tamita K, Shiratori K, Kinoshita M, Senda M, Okada Y, Morioka S. Annular geometry in patients with chronic ischemic mitral regurgitation: three-dimensional magnetic resonance imaging study. Circulation. 2005; 112 (suppl): I-409-I-414.

21. McGee EC, Gillinov AM, Blackstone EH, Rajeswaran J, Cohen G, Najam F, Shiota T, Sabik JF, Lytle BW, McCarthy PM, Cosgrove DM. Recurrent mitral regurgitation after annuloplasty for functional ischemic mitral regurgitation. J Thorac Cardiovasc Surg. Dec 2004;128(6):916-924.

22. Alfieri O, Maisano F, De Bonis M, et al. The double-orifice technique in mitral valve repair: a simple solution for complex problems. J Thorac Cardiovasc Surg 2001;122:674-81

23. Maisano F, Viganò G, Blasio A, et al. Surgical isolated edge-to-edge mitral valve repair without annuloplasty: clinical proof of the principle for an endovascular approach. Eurolnterv 2006;2:181- 6.

24. Alfieri O, Maisano F, DeBonis M, et al. The edge-to-edge technique in mitral valve repair: a simple solution for complex problems. J Thorac Cardiovasc Surg 2001;122:674-81.

25. Maisano F, Torracca L, Oppizzi M, et al. The edge-to-edge technique: a simplified method to correct mitral insufficiency. Eur J Cardiothorac Surg 1998; 13:240-5

26. Maisano F, Schreuder JJ, Oppizzi M, Fiorani B, Fino C, Alfieri O. The double orifice technique as a standardized approach to treat mitral regurgitation due to severe myxomatous disease: surgical technique. Eur J Cardiothorac Surg 2000;17:201-15.

27. Alfieri O, Maisano F, De Bonis M, Stefano PL, Torracca L, Oppizzi M, La Canna $G$. The double-orifice technique in mitral valve repair: a simple solution for complex problems. J Thorac Cardiovasc Surg. Oct 2001;122(4):674-681.

28. Maisano F, Caldarola A, Blasio A, De Bonis M, La Canna G, Alfieri O. Midterm results of edge-to-edge mitral valve repair without annuloplasty. J Thorac Cardiovasc Surg. Dec 2003;126(6):1987-1997.

29. Maisano F, Vigano G, Calabrese C, Taramasso M, Denti P, Blasio A, Guidotti A, Alfieri O. Quality of life of elderly patients following valve surgery for chronic organic mitral regurgitation. Eur J Cardiothorac Surg. Apr 142009.

30. St Goar FG, Fann JI, Komtebedde J, Foster E, Oz MC, Fogarty TJ, Feldman T, Block PC. Endovascular edge-to-edge mitralvalve repair: short-term results in a porcine model. Circulation. Oct 21 2003;108(16):1990-1993.
31. Condado JA, Acquatella H, Rodriguez L, Whitlow P, Velez-Gimo M, St Goar FG. Percutaneous edge-to-edgemitralvalverepair:2-yearfollow-up in the first human case. Catheter Cardiovasc Interv. Feb 2006;67(2):323-325.

32. Feldman T, Wasserman HS, Herrmann HC, Gray W, Block PC, Whitlow P, St Goar F, Rodriguez L, Silvestry F, Schwartz A, Sanborn TA, Condado JA Foster E. Percutaneous mitral valve repair using the edge-to-edge technique: six-month results of the EVEREST Phase I Clinical Trial. J Am Coll Cardiol. Dec 6 2005;46(11):2134-2140.

33. Feldman T, Kar S, Rinaldi M, Fail P, Hermiller J, Smalling R, Whitlow PL, Gray W, Low R, Herrmann HC, Lim S, Foster E, Glower D, for the EVEREST Investigators. Percutaneous mitral repair with the MitraClip system: safety and midterm durability in the initial EVEREST (Endovascular Valve Edge-to-Edge REpair Study) cohort. J. Am. Coll. Cardiol, 2009;54;686-694.

34. Feldman T, et al. Percutaneous repair or surgey for mitral regurgitation. $N$ Engl J Med 2011, 364: 1395-1406.

35. Siegel RJ, Biner S, Rafique AM, Rinaldi M, Lim S, Fail P, Hermiller J, SmaIling R, Whitlow PL, Herrmann HC, Foster E, Feldman T, Glower D, Kar S, and EVEREST Investigators. The acute hemodynamic effects of MitraClip therapy. Am. Coll. Cardiol. 2011;57;1658-1665J.

36. Whitlow PL, Feldman T, et al. Acute and 12-months results with catheter-based mitral valve leaflet repair; the EVEREST II (Endovascular Valve Edge-to Edge Repair) High Risk Study. J Am Coll Cardiol 2012. 59: (2): 130 139.

37. George JC, Varghese V, Dangas G, Feldman TE. Percutaneous mitral valve repair: lessons from the EVEREST II (Endovascular Valve Edge to edge Repair Study) and beyond. JACC Cardiovasc Interv. 2011; 7: 825-827.

38. Mauri L, et al. 4-Year Results of a Randomized Controlled Trial of Percutaneous Repair Versus Surgery for Mitral Regurgitation. J Am Coll Cardiol 2013; 62: 317-328.

39. Maniu CV, Patel JB, Reuter DG, Meyer DM, Edwards WD, Rihal CS, Redfield MM. Acute and chronic reduction of functional mitral regurgitation in experimental heart failure by percutaneous mitral annuloplasty. J Am Coll Cardiol. Oct 19 2004:44(8):1652-1661.

40. Siminiak T, Hoppe UC, Schofer J, Haude M, Herrman JP, Vainer J, Firek L Reuter DG, Goldberg SL, Van Bibber R. Effectiveness and safety of percutaneous coronary sinus-based mitral valve repair in patients with dilated cardiomyopathy (from the AMADEUS trial). Am J Cardiol. 2009 Aug 15:104(4):565-70.

41. WebbJG, HarnekJ, Munt BI, KimbladPO, ChandavimolM, Thompson CR, Mayo JR, Solem JO. Percutaneous transvenous mitral annuloplasty: initial human experience with device implantation in the coronary sinus. Circulation. Feb 14 2006;113(6):851-855.

42. Daimon M, Gillinov A, Liddicoat J, et al. Dynamic change in mitral annular area and motion during percutaneous mitral annuloplasty for ischemic mitral regurgitation: preliminary animal study with real-time 3-dimensional echocardiography. J Am Soc Echocardiogr 2007;20:381-8.

43. Dubreuil O, Basmadjian A, Ducharme A, et al. Percutaneous mitral valve annuloplasty for ischemic mitral regurgitation: first in man experience with a temporary implant. Catheter Cardiovasc Interv 2007;69:1053-61.

44. Sack S, Kahlert P, Bilodeau L, et al. Percutaneous transvenous mitral annuloplasty: initial human experience with a novel coronary sinus implant device. Circ Cardiovasc Interv 2009;2;277-84.

45. Liddicoat JR, Mac Neill BD, Gillinov AM, Cohn WE, Chin CH, Prado AD, Pandian NG, Oesterle SN. Percutaneous mitral valve repair: a feasibility study in an ovine model of acute ischemic mitral regurgitation. Catheter Cardiovasc Interv. Nov 2003;60(3):410-416.

46. Dubreuil O, Basmadjian A, Ducharme A, Thibault B, Crepeau J, Lam JY, Bilodeau L. Percutaneous mitral valve annuloplasty for ischemic mitral regurgitation: first in man experience with a temporary implant. Catheter Cardiovasc Interv. Jun 1 2007;69(7):1053-1061.

47. Aybek T, Risteski P, Miskovic A, Simon A, Dogan S, Abdel-Rahman U, Moritz A. Seven years' experience with suture annuloplasty for mitral valve repair. The Journal of thoracic and cardiovascular surgery. Jan 2006;131(1):99-106.

48. Heuser RR, Witzel T, Dickens D, Takeda PA. Percutaneous treatment for mi tral regurgitation: the QuantumCor system. Journal of interventional cardiology. Apr 2008;21(2):178-182.

49. Rogers JH, Macoviak JA, Rahdert DA, Takeda PA, Palacios IF, Low RI. Percutaneous septal sinus shortening: a novel procedure for the treatment of functional mitral regurgitation. Circulation. May 16 2006;113(19):23292334. 
50. Palacios IF, Condado JA, Brandi S, Rodriguez V, Bosch F, Silva G, Low RI, Rogers JH. Safety and feasibility of acute percutaneous septal sinus shortening: first-in-human experience. Catheter Cardiovasc Interv. Mar 1 2007;69(4):513-518.

51. Pedersen WR, Block P, Leon M, Kramer P, Kapadia S, Babaliaros V, KodaIi S, Tuzcu EM, Feldman T. iCoapsys mitral valve repair system: Percutaneous implantation in an animal model. Catheter Cardiovasc Interv. Jul 12008;72(1):125-131.

52. Jindani A, Neville EM, Venn G, Williams BT. Paraprosthetic leak: a complication of cardiac valve replacement. The Journal of cardiovascular surgery. Jul-Aug 1991;32(4):503-508.

53. Safi AM, Kwan T, Afflu E, Al Kamme A, Salciccioli L. Paravalvular regurgitation: a rare complication following valve replacement surgery. Angiology. Jun 2000;51(6):479-487.

54. Echevarria JR, Bernal JM, Rabasa JM, Morales D, Revilla Y, Revuelta JM. Reoperation for bioprosthetic valve dysfunction. A decade of clinical experience. Eur J Cardiothorac Surg. 1991;5(10):523-526; discussion 527.

55. Pate GE, Al Zubaidi A, Chandavimol M, Thompson CR, Munt BI, Webb JG. Percutaneous closure of prosthetic paravalvular leaks: case series and review. Catheter Cardiovasc Interv. Oct 2006;68(4):528-533.
56. Kort HW, Sharkey AM, BalzerDT. Novel use of the Amplatzer duct occluder to close perivalvar leak involving a prosthetic mitral valve. Catheter Cardiovasc Interv. Apr 2004;61(4):548-551.

57. Webb JG, Pate GE, Munt BI. Percutaneous closure of an aortic prosthetic paravalvular leak with an Amplatzer duct occluder. Catheter Cardiovasc Interv. May 2005;65(1):69-72.

58. Johri AM, Yared K, Durst R, Cubeddu RJ, Palacios IF, Picard MH, Passeri $J$. Three-dimensional echocardiography-guided repair of severe paravalvular regurgitation in a bioprosthetic and mechanical mitral valve. Eur J Echocardiogr. Mar 82009.

59. Messas E, Guerrero JL, HandschumacherMD, Conrad C, Chow C-M, SuIlivan S, Yoganathan AP, Levine RA. Chordal cutting: a new therapeutic approach for ischemic mitral regurgitation. Circulation. 2001;104: $1958-1963$

60. Maisano F, Michev I, Rowe S, Vigano G, Addis A, Alfieri O, Campagnol M, Guidotti A, Colombo A, Alfieri O. Transapical endovascular implantation of neochordae using a suction and suture device. Eur J Cardiothorac Surg. 2009: 36 91): 118-123. 